BMC

Gastroenterology

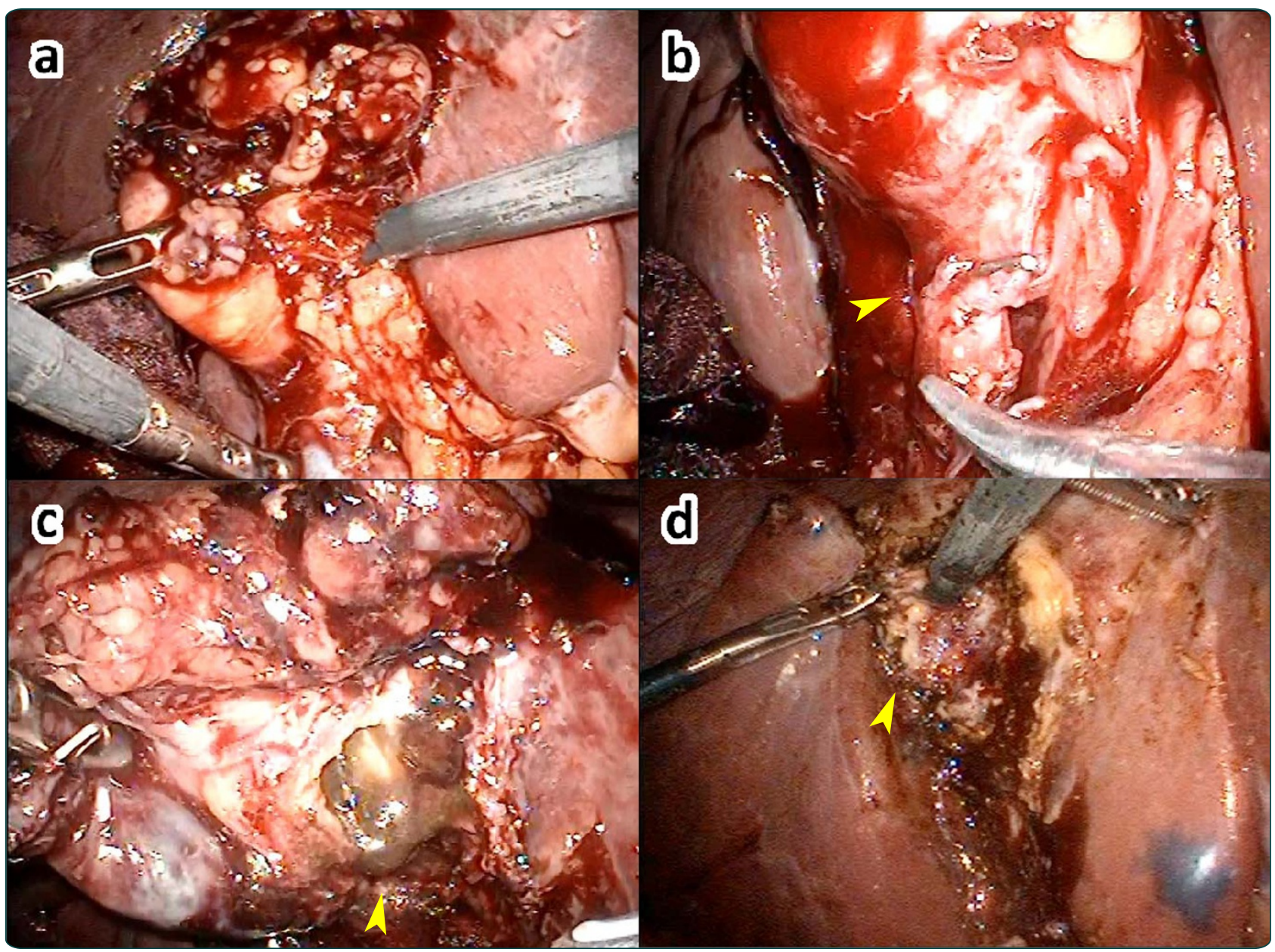

\title{
Cholecystomucoclasis: revaluation of safety and validity in aged populations
}

Tsukada et al. 


\title{
Cholecystomucoclasis: revaluation of safety and validity in aged populations
}

Tomoya Tsukada ${ }^{1,2^{*}}$, Tatsuo Nakano ${ }^{2}$, Takashi Miyata ${ }^{2}$, Shozo Sasaki ${ }^{2}$ and Tetsuo Ohta ${ }^{1}$

\begin{abstract}
Background: We evaluated the safety and validity of cholecystomucoclasis (CM) and compared its intraoperative characteristics with those of standard cholecystectomy (SC).

Methods: We enrolled 174 patients who underwent cholecystectomy and retrospectively evaluated the outcomes of patients in the SC and CM groups.

Results: Significant differences in age (71.1 vs. 61.9 years), American Society of Anesthesiologists physical status (ASA-PS), and serum C-reactive protein levels (CRP) (18.1 vs. $4.7 \mathrm{mg} / \mathrm{dL})$ were observed between the CM and SC groups. Conversely, no significant differences were observed in the operation time (129 vs. $108 \mathrm{~min}$ ), amount of blood loss (147 vs. $80 \mathrm{~mL}$ ), intraoperative complications (0\% vs. 5.7\%), or duration of hospital stay (13.2 vs. 8.9 days) between the 2 groups. A high conversion rate (35.3\%), postoperative complications (33\%), and frequent drain insertions (94\%) were observed in the CM group.

Conclusions: CM is a safe and valid surgical procedure and surgeons should not hesitate to transition to CM for patients who are of advanced age, in poor general condition (high ASA classification), or have high levels of serum CRP.
\end{abstract}

Keywords: Cholecystitis, Cholecystomucoclasis, Deroofing, Subtotal cholecystectomy

\section{Background}

Cholecystectomy, particularly laparoscopic cholecystectomy (LC), has become the standard treatment for patients with benign gallbladder disease [1-3]. Although the indications for surgery in patients with acute cholecystitis have been expanding [4-6], there are cases where standard cholecystectomy (SC) is difficult owing to the presence of acute or chronic inflammation, strong omental adhesion, or gangrenous cholecystitis. As patients with benign gallbladder disease tend to be of advanced age, safer and more feasible surgical techniques are required for difficult cases [7-9].

Cholecystomucoclasis (CM) is a traditional method that is combined with subtotal cholecystectomy and involves the cauterization of the posterior gallbladder wall preserved in the liver bed that remains after

\footnotetext{
* Correspondence: tkd_tmy@nifty.com
${ }^{1}$ Department of Gastroenterological Surgery, Division of Cancer Medicine,

* Correspondence: tkd_tmy@nifty.com
${ }^{1}$ Department of Gastroenterological Surgery, Division of Cancer Medicine, Graduate School of Medical Science, Kanazawa University, 3-1 Takara-machi, Kanazawa, Ishikawa 920-8641, Japan

2Department of Surgery, Asanogawa General Hospital, Kanazawa, Ishikawa 920-8621, Japan
}

(c) 2012 Tsukada et al.; licensee BioMed Central Ltd. This is an Open Access article distributed under the terms of the Creative Commons Attribution License (http://creativecommons.org/licenses/by/2.0), which permits unrestricted use, distribution, and reproduction in any medium, provided the original work is properly cited.

\section{Methods}

Patients

As shown in Table 1, 174 patients (93 men and 81 women) underwent cholecystectomy at the Department of Surgery, Asanogawa General Hospital, Kanazawa, Japan, between January 2007 and December 2011, excluding those who were diagnosed with malignancy and underwent choledocholithotomy or simultaneous resection of other organs. matory cholecystitis [10]. CM, also called deroofing of ince . and other advanced techniques have shown that CM is a safe and feasible option [16-21]. However, preoperative conditions and intraoperative technical characteristics been less well described. Hence, we revaluated the safety and validity of $\mathrm{CM}$ and compared its intraoperative characteristics with those of SC.

\section{Biomed Central}


Table 1 Patient characteristics and surgical procedures

\begin{tabular}{ll}
\hline & Number (\%) \\
\hline Patients & 174 \\
\hline Male & $93(53.4)$ \\
\hline Age (years) & $81(46.6)$ \\
\hline Mean & $62.9 \pm 14.3$ \\
\hline Range & $23-95$ \\
\hline ASA-PS classification & \\
\hline 1 & $39(22.4)$ \\
\hline 2 & $97(55.7)$ \\
\hline 3 & $34(19.5)$ \\
\hline 4 & $4(2.3)$ \\
\hline Surgical procedures & $18(10.3)$ \\
\hline Cholecystomucoclasis (deroofing) & $163(93.7)$ \\
\hline Laparoscopic cholecystectomy (conventional) & $18(10.3)$ \\
\hline SILC & $11(6.3)$ \\
\hline Open cholecystectomy & $13(7.5)$ \\
\hline Conversion (laparoscopic to open)
\end{tabular}

ASA-PS: American Society of Anesthesiologists physical status. SILC: Single-incision laparoscopic cholecystectomy.

The average age of the patients was $62.9 \pm 14.3$ years (range, 23-95 years). Preoperative clinical diagnoses of cholecystitis were made on the basis of each patient's history of right upper abdominal pain and tenderness, fever, leukocytosis, increased C-reactive protein (CRP) levels, and positive signs on computed tomography or ultrasonography (thickened gallbladder wall and pericholecystic fluid collection). All resected specimens were also evaluated histopathologically. This study was approved by the Institutional Review Board of the Asanogawa General Hospital (AGH-IRB No. 22).

\section{Operative technique}

LC was performed by the standard 3 or 4-trocar technique. Briefly, the anesthetized patient was placed in the standard supine, crucifix, reverse-Trendelenburg position, with the surgeon on the patient's left side. Pneumoperitoneum was achieved by visually guided, cannular $\mathrm{CO}_{2}$ insufflation. The dissection was started at the Calot's triangle, and the cystic duct, the common bile duct, and the cystic artery were exposed and divided between clips. Intraoperative cholangiography was routinely performed to detect residual calculus and bile duct injury. The gallbladder itself was carefully mobilized from the liver bed using electrocautery. An endobag was always used to remove the gallbladder, thus preventing wound infection. The abdominal cavity was irrigated before the trocars were removed, and the fascial defects were closed.
In April 2010, single-incision laparoscopic cholecystectomy (SILC) was instituted at our institution and subsequent LCs were performed using this technique. For the SILC technique, the patient was positioned supine on the operating table with the legs widely separated. The surgeon stood between the patient's legs, and the cameraperson stood to the right of the surgeon (near the patient's left leg) [22]. A 2-cm vertical transumbilical incision was made, and either a SILS port (Covidien Inc., Norwalk, CT, USA) or the hand-made glove method was used [23]. A 5-mm flexible endoscope (Olympus, Tokyo, Japan) was used for intraabdominal visualization. Cholecystectomy was then performed as mentioned above and as described previously $[24,25]$.

Open cholecystectomy (OC) was performed through a right subcostal or a midline incision. In almost all cases, decompression of the gallbladder was performed using needle aspiration. Dissection was performed to identify the cystic duct and the common bile duct. In cases of advanced local inflammation, the dissection was performed from the fundus towards Calot's triangle. Intraoperative cholangiography was routinely performed. Finally, the gallbladder was removed from the liver bed.

In principle, the gallbladder should be totally resected. However, CM was considered, at the discretion of the surgeon, to prevent massive bleeding or bile duct injury. In particular, CM was applied in cases of a thinned necrotic gallbladder wall due to advanced inflammation, a thickened sclerotic gallbladder wall because of advanced inflammation, the inability to determine the exact orientation of the Calot's triangle, and the burial of the gallbladder deep within the liver bed. In severe, gangrenous cholecystitis, the dissection began from the fundus to the neck of the gallbladder, after decompression of the gallbladder. The residual gallbladder mucosa was cauterized by electrocautery or argon plasma coagulation. If the gallbladder wall was accidentally damaged, the gallbladder was continuously dissected from the orifice (Figure 1, 2).

\section{Data collection}

The data were retrospectively collected from medical records, operative reports, and histopathological reports. The outcomes for the SC and CM groups were evaluated. The outcome measures included the conversion rate (laparoscopic to open), operation time, loss of blood (low bleeding was defined as $0 \mathrm{~mL}$ ), maximum preoperative CRP level, American Society of Anesthesiologists physical status (ASA-PS) score, success rate of intraoperative cholangiography, treatment of the proximal bile duct stump, intraoperative complications, postoperative complications, presence or absence of a drain, and length of hospital stay. 

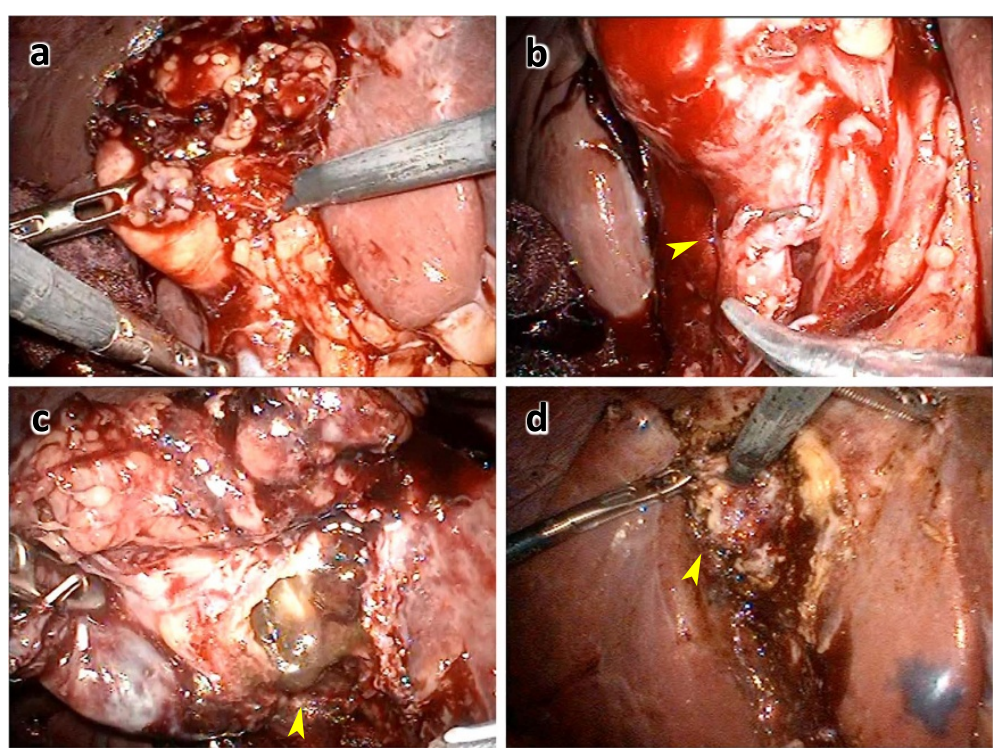

Figure 1 Representative intraoperative findings of cholecystomucoclasis for acute cholecystitis. a: Overview of acute cholecystitis. $\mathbf{b}$ : Double-clipped cystic artery (arrowhead). c: The gallbladder was incised carefully because of the lack of a clear indication of the correct layer. $\mathbf{d}$ : The gallbladder mucosa cauterized by electrocautery (arrowhead).

\section{Statistical analysis}

The values were expressed as means \pm standard deviations (SD). The statistical analysis was conducted using the 2-sided Student's $t$ test and the Mann-Whitney $U$ test for continuous data or Fisher's exact test and the chi-squared test for categorical data. All statistical analyses were performed using the SPSS 10.0 software package (SPSS, Chicago, IL, USA). Significance was defined as $P<0.05$.

\section{Results}

Patient characteristics and preoperative findings

The 174 patients who underwent cholecystectomy were divided into the CM and SC groups. Data from the 2


Figure 2 Representative intraoperative findings of cholecystomucoclasis for atrophic cholecystitis. a: Overview of atrophic gallbladder in chronic cholecystitis. $\mathbf{b}$ : Injury of the gallbladder body wall while dissecting from the liver bed. The gallbladder mucosa and gallstones were exposed (arrowhead). c: The gallbladder was incised consecutively from the site of the exposed gallbladder mucosa. $\mathbf{d}$ : Overview after gallbladder removal showing the residual gallbladder posterior wall (arrowhead). 
groups are summarized in Table 2. In the CM group, the laparoscopic approach was used for 17 patients, but SILC was not applied. There was no difference in the sex ratio of the 2 groups $(P=0.491)$. Patients in the $\mathrm{CM}$ group were, on average, almost 10 years older than those in the $\mathrm{SC}$ group $(P=0.006)$. The preoperative general condition was assessed according to the ASA-PS score. The CM group tended to include patients with scores indicating greater severity $(P=0.038)$, and all patients with lifethreatening indications (classified as grade 4 ) underwent SC. Preoperative laboratory data showed a significant difference in CRP levels between the CM and SC groups $(18.1 \pm 10.5 \mathrm{mg} / \mathrm{dL}$ vs. $4.7 \pm 8.1 \mathrm{mg} / \mathrm{dL}, P<0.001)$.

\section{Operative findings}

The mean operation time was 129 min (range, 63-190 $\mathrm{min}$ ) for the $\mathrm{CM}$ group and $108 \mathrm{~min}$ (range, 50-375 min) for the SC group $(P=0.084)$. The extent of bleeding was not significantly different between the 2 groups $(P=0.247)$. Intraoperative cholangiography was routinely attempted in all cases. The success rate for intraoperative cholangiography was significantly lower in the CM group (50\% [9/18]) than in the SC group (92.9\% [145/156], $P<0.001)$. When the anatomy of the Calot's triangle was unclear or inflammation in the gallbladder neck was advanced, the bile duct stump was treated at the neck and the cholecystectomy was limited to a

Table 2 Characterization of the cholecystomucoclasis and standard cholecystectomy groups, preoperative findings, and conversion rates

\begin{tabular}{|c|c|c|c|}
\hline & $\mathrm{CM}$ & SC & $P$ value \\
\hline & $(n=18)$ & $(n=156)$ & \\
\hline Sex & & & 0.491 \\
\hline Male & 11 & 82 & \\
\hline Female & 7 & 74 & \\
\hline Age (years) & & & 0.006 \\
\hline Mean & $71.1 \pm 8.4$ & $61.9 \pm 14.6$ & \\
\hline Range & $58-84$ & $23-95$ & \\
\hline ASA-PS classification & & & 0.038 \\
\hline 1 & 2 & 37 & \\
\hline 2 & 8 & 89 & \\
\hline 3 & 8 & 26 & \\
\hline 4 & 0 & 4 & \\
\hline Mean CRP in mg/dL & $18.1 \pm 10.5$ & $4.7 \pm 8.1$ & $<0.001$ \\
\hline Range CRP in mg/dL & $0.41-36.20$ & $0.02-34.04$ & \\
\hline \multicolumn{4}{|c|}{ Approach to laparotomy } \\
\hline LC (conventional) & 17 & 128 & \\
\hline SILC & 0 & 18 & \\
\hline OC & 1 & 10 & \\
\hline
\end{tabular}

CRP: C-reactive protein, LC: Laparoscopic cholecystectomy, SILC: Single-incision laparoscopic cholecystectomy, OC: Open cholecystectomy. partial resection. The site of the proximal bile duct stump was examined in the 2 groups. The number of patients treated at the neck of gallbladder was significantly more in the $\mathrm{CM}$ group than in the $\mathrm{SC}$ group $(P<0.001)$. The treatment of the stump of the proximal bile duct was also investigated; a clip was used for almost all patients of the SC group (84.0\% [131/156]), whereas various methods (e.g., endoloop, ligation, suture, and elastic yarn) were used for patients in the CM group. In the CM group, the stump could not be closed in 2 patients; thus, only drainage was applied.

Conversion from LC to open cholecystectomy (OC) was usually implemented to prevent bile duct injury within $30 \mathrm{~min}$ of beginning the laparoscopy. In some cases (e.g., massive bleeding from the liver bed or identification of bile duct injury after intraoperative cholangiography), OC was used to repair the damage. The conversion rate was significantly higher in the CM group $(35.3 \%$ [6/17]) than in the SC group (4.8\% [7/146], $P<0.001$ ) (Table 3).

\section{Complications and adequacy}

The intraoperative and postoperative complications are described in Table 4. Although the 2 groups did not differ significantly in this regard $(P=0.578)$, the $\mathrm{CM}$ group

\section{Table 3 Operative findings}

\begin{tabular}{|c|c|c|c|}
\hline & CM & SC & $P$ value \\
\hline & $(n=18)$ & $(n=156)$ & \\
\hline \multicolumn{4}{|l|}{ Operation time (min) } \\
\hline Mean & $129 \pm 34$ & $108 \pm 48$ & 0.084 \\
\hline Range & $63-190$ & $50-375$ & \\
\hline \multicolumn{4}{|l|}{ Amount of bleeding (mL) } \\
\hline Mean & $146.7 \pm 185.2$ & $79.7 \pm 236.4$ & 0.247 \\
\hline Range & $0-675$ & $0-1970$ & \\
\hline Success rate of & & & $<0.001$ \\
\hline \multicolumn{4}{|l|}{ intraoperative cholangiography } \\
\hline Possible & 9 & 145 & \\
\hline Not possible & 9 & 11 & \\
\hline Site of proximal bile duct stump & & & $<0.001$ \\
\hline Cystic duct & 11 & 148 & \\
\hline Neck of gallbladder & 7 & 8 & \\
\hline \multicolumn{4}{|l|}{ Methodology of treatment } \\
\hline \multicolumn{4}{|l|}{ for bile duct stump } \\
\hline Clip & 6 & 131 & $<0.001$ \\
\hline Endoloop & 1 & 2 & \\
\hline Ligation & 4 & 7 & \\
\hline Suture & 3 & 6 & \\
\hline Elastic yarn (for transcystic drainage) & 2 & 10 & \\
\hline None & 2 & 0 & \\
\hline Conversion rate (\%) & $6 / 17(35.3)$ & $7 / 146(4.8)$ & $<0.001$ \\
\hline
\end{tabular}

CM: Cholecystomucoclasis, SC: Standard cholecystectomy. 
Table 4 Complications, reoperations, additional treatments, drains, and lengths of hospital stay

\begin{tabular}{|c|c|c|c|}
\hline & $\mathrm{CM}$ & SC & $P$ value \\
\hline & $(n=18)$ & $\overline{(n=156)}$ & \\
\hline Intraoperative complications & & & 0.578 \\
\hline Total & 0 & 9 & \\
\hline Massive bleeding (>1000 mL) & 0 & 3 & \\
\hline Bile duct injury & 0 & 6 & \\
\hline Postoperative complications & & & 0.001 \\
\hline Total & 6 & 10 & \\
\hline Major intra-abdominal bleeding & 0 & 2 & \\
\hline Bile leakage & 2 & 4 & \\
\hline Wound infection & 3 & 2 & \\
\hline Bacteremia (catheter infection) & 0 & 1 & \\
\hline Retained calculus & 1 & 1 & \\
\hline Reoperation & 0 & 3 & 0.839 \\
\hline Major intra-abdominal bleeding & 0 & 1 & \\
\hline Bile leakage & 0 & 2 & \\
\hline Additional treatment (EBD, PTCD) & 1 & 4 & 0.06 \\
\hline Drain & & & $<0.001$ \\
\hline Presence & 17 & 61 & \\
\hline Absence & 1 & 95 & \\
\hline Hospital stay (days) & & & 0.495 \\
\hline Mean & $13.2 \pm 6.4$ & $8.9 \pm 26.1$ & \\
\hline Range & $5-27$ & $3-330$ & \\
\hline
\end{tabular}

CM: Cholecystomucoclasis, SC: Standard cholecystectomy, EBD: Endoscopic biliary drainage, PTCD: Percutaneous transhepatic cholangial drainage.

had no intraoperative complications, whereas the SC group had a relatively high incidence of complications (Figure 3). Three cases of massive bleeding (>1000 mL) and 6 cases of bile duct injury were observed in the SC group.
Postoperative complications were observed in 4 patients of the CM group. Bile leakage and wound infection occurred in 2 patients and a residual calculus, which was subsequently removed endoscopically, was observed in 1 patient. Additional surgical treatment was not required for any of the $\mathrm{CM}$ patients. In the SC group, postoperative complications were observed in 10 patients. Two patients experienced intra-abdominal hemorrhage: 1 patient required reoperation and the other was treated conservatively with blood transfusions. Bile leakage was observed in 4 patients: 1 was treated conservatively, 1 needed endoscopic drainage, 1 required immediate reoperation, and 1 required reoperation even though endoscopic drainage and percutaneous transhepatic cholangial drainage were both attempted.

A drain was inserted into the liver bed in almost all CM patients (17/18), but only in some of the SC patients $(61 / 156, P<0.001)$. The average length of the hospital stay was $13.2 \pm 6.4$ days (range, 5-27 days) in the CM group and $8.9 \pm 26.1$ days (range, $3-330$ days) in the SC group $(P=0.495)$.

Histopathological examination was performed for all patients, with gallbladder cancer being diagnosed in 2 patients, who received additional treatment. No mortality was associated with the procedures in either group.

\section{Discussion}

Difficulties in performing cholecystectomy include a lack of clarity of the anatomical orientation of the Calot's triangle, resulting from severe, acute inflammation or chronic atrophic sclerotic change. In this situation, subtotal cholecystectomy is recommended for a safe surgery. Subtotal cholecystectomy can be performed using 2 methods: dissecting the neck of the gallbladder rather than approaching the Calot's triangle to prevent bile

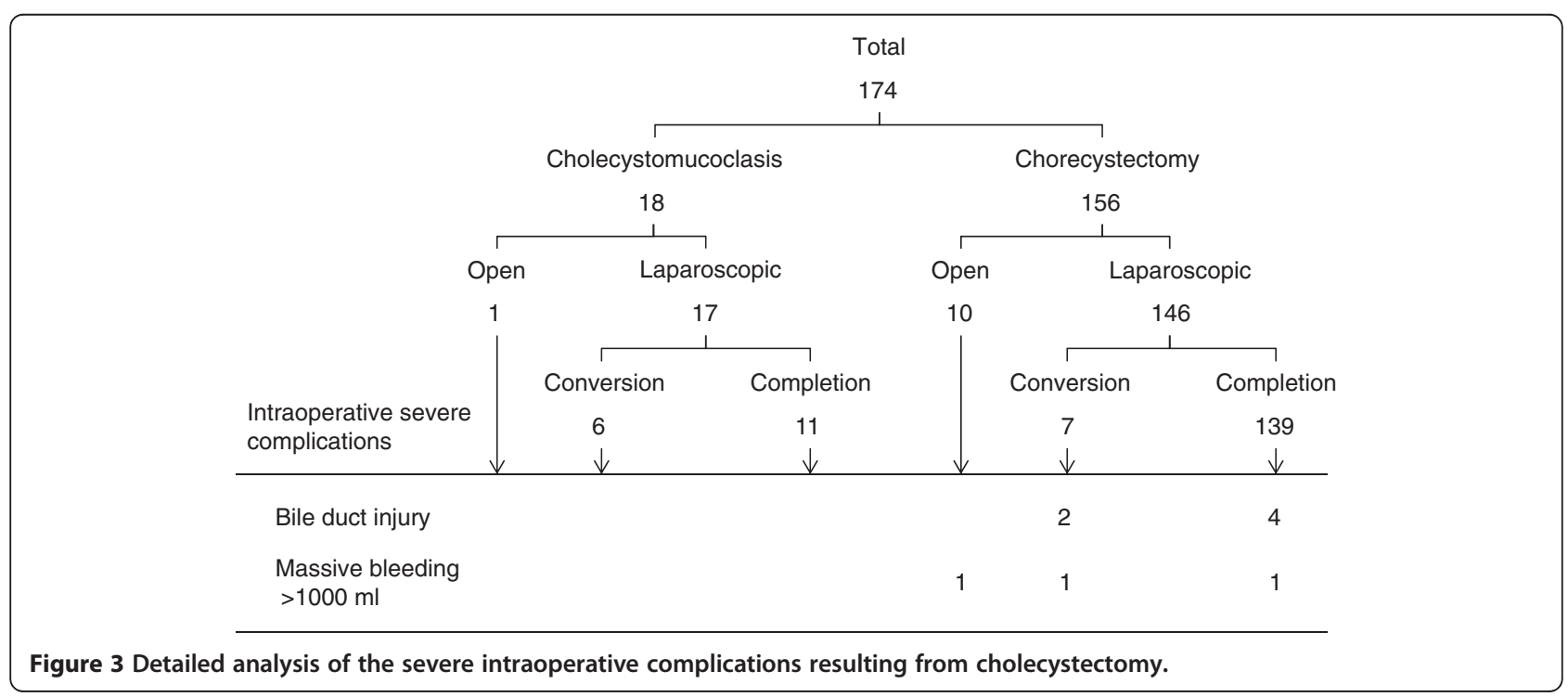


duct injury or not removing the posterior wall of the gallbladder to prevent bleeding from the liver bed. In the latter method, ablation of the remaining mucosa is common and is referred to as CM.

In principle, the gallbladder should be completely resected, as gallbladder carcinoma has been reported in $0.3-1.5 \%$ of patients who have undergone cholecystectomy [26,27]; therefore, it is necessary to check for any signs of malignancy during preoperative diagnostic imaging. Because CM or subtotal cholecystectomy may result in an intraoperative bile leak into the abdominal cavity, these procedures are associated with potential dissemination. Although there are no reports of residual gallbladder cancer following CM or subtotal cholecystectomy, Shimizu et al. reported a case of biliary tract cancer in the liver bed after subtotal cholecystectomy. They considered the possibility of a peripheral type of intrahepatic cholangiocarcinoma as well as carcinomas from the residual gallbladder mucosa or the Luschka duct [28]. Therefore, regular follow-ups with diagnostic imaging are needed, even when the patient does not show pathological evidence of malignancy.

The frequency of postoperative complications in subtotal cholecystectomies has been reported to be 6.7$20.7 \%$ [17-21], with the patients having an average age of 53-62.9 years. In the current study, a relatively high incidence of postoperative complications (33\% [6/18]) was observed, and the average age of patients in the CM group was $71.1 \pm 8.4$ years. In particular, 2 patients were found to have postoperative bile leakage, both of whom were treated with drainage only, without processing of the bile duct stump. One patient required endoscopic biliary drainage (EBD) and the other recovered spontaneously without any additional treatment. The reason for the spontaneous closure was presumed to be the result of postoperative firm adhesion and scar formation, which is expected in patients with advanced inflammation. The SC group had 4 patients with postoperative bile leakage. Two patients required a reoperation for bile leakage closure, and the other 2 were treated by diversion of bile from the leakage site by EBD or percutaneous transhepatic cholangial drainage. There were no significant differences between the two groups in additional treatment $(P=0.06)$, but the treatment for bile leakage in SC group was more difficult.

Few detailed studies have reported on intraoperative findings in these types of cholecystectomies. In the CM group, there was no evidence of intraoperative damage to the biliary tract, a finding that was similar in the SC group. Additionally, there was no significant difference in the amount of bleeding between the 2 groups, and the CM group did not include patients exhibiting massive bleeding (>1000 mL). During cholecystectomy, bleeding primarily originates from the cystic arteries and the liver bed; CM and subtotal cholecystectomy help prevent bleeding from these important locations.

The conversion rate to OC was $35.3 \%$ in the CM group, which was higher than that in previous reports $(1.7-7.7 \%)$ [18.19.21]. Thus, we emphasize on safety in our surgical procedures and convert to OC without hesitation in difficult cases. The lack of intraoperative complications in the CM group is probably the result of these efforts. Furthermore, patients who needed reoperation were observed only in the SC group, highlighting the need for a flexible approach according to patient characteristics rather than adherence to a particular policy of laparoscopic surgery in order to avoid unnecessary intraoperative complications and conversion to laparotomy.

OCs are typically more closely associated with advanced age, poor general condition, or a high inflammatory response than are laparoscopic surgeries [29]. These same characteristics are also associated with an increased severity of acute cholecystitis, which may result in a more difficult surgery. The aforementioned patient characteristics are collective, but not independent, risk factors for postoperative complications of acute gangrenous cholecystitis [30,31]. In addition, Schäfer et al. have reported that advanced age and a high serum CRP level may be predictive factors for the surgical procedures that are used in patients undergoing laparotomy and patients who were converted to laparotomy [32]. The current study was a retrospective study, with a selection bias based on intraoperative findings; the $\mathrm{CM}$ group showed an advanced age and a high serum CRP level. With the transition to $\mathrm{CM}$ and open surgery in mind, the conversion to a safe surgical procedure should be considered in elderly patients with high inflammation of the gallbladder neck.

\section{Conclusions}

The intraoperative technical characteristics of SC and $\mathrm{CM}$ were analyzed, and a low rate of handling of the cystic duct stump and a low success rate for intraoperative cholangiography were observed in the CM group. However, no significant differences were observed in the operative time, amount of bleeding, and number of intraoperative complications. Compared with SC, high conversion rates and drain insertion rates were noted in patients undergoing $\mathrm{CM}$, but the length of hospital stay did not differ significantly. CM is thus considered to be a safe and valid surgical procedure. In addition, surgeons should not hesitate to transition to CM for patients with advanced age, poor general condition (high ASA classification), and a high serum CRP level.

Competing interests

The authors declare that they have no conflicts of interest. 


\section{Authors' contributions}

TT performed most of the experiments, participated in the design of the study, performed the statistical analysis, and drafted the manuscript. TO was involved in the study design and coordination. TM, SS, and TN participated in the design of the study and helped draft the manuscript. All authors have read and approved the final manuscript.

Received: 26 February 2012 Accepted: 13 August 2012

Published: 21 August 2012

\section{References}

1. Scott TR, Zucker KA, Bailey RW: Laparoscopic cholecystectomy: a review of 12,397 patients. Surg Laparosc Endosc 1992, 2:191-198.

2. Perissat J: Laparoscopic cholecystectomy: the European experience. Am J Surg 1993, 165:444-449.

3. Johansson M, Thune A, Nelvin L, Lundell L: Randomized clinical trial of day-care versus overnight-stay laparoscopic cholecystectomy. $\mathrm{Br}$ J Surg 2006, 93:40-45.

4. Sinha R, Sharma N: Acute cholecystitis and laparoscopic cholecystectomy. JSLS 2002, 6:65-68.

5. Kitano S, Matsumoto T, Aramaki M, Kawano K: Laparoscopic cholecystectomy for acute cholecystitis. J Hepatobiliary Pancreat Surg 2002, 9:534-547.

6. Al Salamah SM: Outcome of laparoscopic cholecystectomy in acute cholecystitis. J Coll Physicians Surg Pak 2005, 15:400-403.

7. Pavlidis TE, Marakis GN, Symeonidis N, Psarras K, Ballas K, Rafailidis S, Sakantamis AK: Considerations concerning laparoscopic cholecystectomy in the extremely elderly. J Laparoendosc Adv Surg Tech A. 2008, 18:56-60.

8. Sugiyama M, Tokuhara M, Atomi Y: Is percutaneous cholecystostomy the optimal treatment for acute cholecystitis in the very elderly? World J Surg 1998, 22:459-463.

9. Tucker JJ, Yanagawa F, Grim R, Bell T, Ahuja V: Laparoscopic cholecystectomy is safe but underused in the elderly. Am Surg 2011, 77:1014-1020.

10. Orator $\mathrm{V}$ : Methods for an ideal cholecystectomy (von Haberer); total subserosa stripping (Pribram) and electrosurgical management (Pribram, Thorek). Zentralb/ Chir 1953, 78:2017-2025.

11. Sistla SC, Sankar G, Basu D, Venkatesan B: Biliary cystadenocarcinoma of the gall bladder: a case report. J Med Case Reports 2009, 3:75.

12. Ota A, Kano N, Kusanagi H, Yamada S, Garg A: Techniques for difficult cases of laparoscopic cholecystectomy. J Hepatobiliary Pancreat Surg 2003, 10:172-175.

13. Douglas PR, Ham JM: Partial cholecystectomy. Aust N Z J Surg 1990, 60:595-597.

14. Bornman PC, Terblanche J: Subtotal cholecystectomy: for the difficult gallbladder in portal hypertension and cholecystitis. Surgery 1985, 98:1-6.

15. Cottier DJ, McKay C, Anderson JR: Subtotal cholecystectomy. Br J Surg 1991, 78:1326-1368.

16. Bickel A, Shtamler B: Laparoscopic subtotal cholecystectomy. J Laparoendosc Surg 1993, 3:365-367.

17. Michalowski K, Bornman PC, Krige JE, Gallagher PJ, Terblanche J: Laparoscopic subtotal cholecystectomy in patients with complicated acute cholecystitis or fibrosis. Br J Surg 1998, 85:904-906.

18. Chowbey PK, Sharma A, Khullar R, Mann V, Baijal M, Vashistha A: Laparoscopic subtotal cholecystectomy: a review of 56 procedures. J Laparoendosc Adv Surg Tech A 2000, 10:31-34.

19. Ji W, Li LT, Li JS: Role of laparoscopic subtotal cholecystectomy in the treatment of complicated cholecystitis. Hepatobiliary Pancreat Dis Int 2006, 5:584-589.

20. Tian Y, Wu SD, Su Y, Kong J, Yu H, Fan Y: Laparoscopic subtotal cholecystectomy as an alternative procedure designed to prevent bile duct injury: experience of a hospital in northern China. Surg Today 2009, 39:510-513.

21. Nakajima J, Sasaki A, Obuchi T, Baba S, Nitta H, Wakabayashi G: Laparoscopic subtotal cholecystectomy for severe cholecystitis. Surg Today 2009, 39:870-875.

22. Adachi T, Okamoto $T$, Ono S, Kanematsu T, Kuroki T: Technical progress in single-incision laparoscopic cholecystectomy in our initial experience. Minim Invasive Surg 2011, 2011:972647. doi:10.1155/2011/972647.
23. Hong TH, You YK, Lee KH: Transumbilical single-port laparoscopic cholecystectomy: scarless cholecystectomy. Surg Endosc 2009, 23:1393-1397.

24. Rivas H, Varela E, Scott D: Single-incision laparoscopic cholecystectomy: initial evaluation of a large series of patients. Surg Endosc 2010, 24:1403-1412.

25. Bhandarkar D, Mittal G, Shah R, Katara A, Udwadia TE: Single-incision laparoscopic cholecystectomy: How I do it? Minim Access Surg 2011, 7:17-23.

26. Legorreta AP, Silber JH, Costantino GN, Kobylinski RW, Zatz SL: Increased cholecystectomy rate after the introduction of laparoscopic cholecystectomy. JAMA 1993, 270:1429-1432.

27. Contini S, Dalla Valle R, Zinicola R: Unexpected gallbladder cancer after laparoscopic cholecystectomy: an emerging problem? Reflections on four cases. Surg Endosc 1999, 13:264-267.

28. Shimizu K, Ohwada S, Fukusato T, Nishijima K, Ohno S, Morishita Y: Adenocarcinoma arising from gallbladder fosa with duodenal involvement 14 years after cholecystectomy: a case report (in Japanese with English abstract). Nihon Shokakibyo Gakkai Zasshi 1996, 93:857-861.

29. Coenye KE, Jourdain S, Mendes da Costa P: Laparoscopic cholecystectomy for acute cholecystitis in the elderly: a retrospective study. Hepatogastroenterology 2005, 52:17-21.

30. Nikfarjam M, Niumsawatt V, Sethu A, Fink MA, Muralidharan V, Starkey G, Jones RM, Christophi C: Outcomes of contemporary management of gangrenous and non-gangrenous acute cholecystitis. HPB (Oxford) 2011, 13:551-558.

31. Moyson J, Thill V, Simoens C, Smets D, Debergh N, Mendes da Costa P: Laparoscopic cholecystectomy for acute cholecystitis in the elderly: a retrospective study of 100 patients. Hepatogastroenterology 2008, 55:1975-1980.

32. Schäfer $M$, Krähenbühl $L$, Büchler MW: Predictive factors for the type of surgery in acute cholecystitis. Am J Surg 2001, 182:291-297.

\section{doi:10.1186/1471-230X-12-113}

Cite this article as: Tsukada et al:: Cholecystomucoclasis: revaluation of safety and validity in aged populations. BMC Gastroenterology 2012 $12: 113$.

\section{Submit your next manuscript to BioMed Central and take full advantage of:}

- Convenient online submission

- Thorough peer review

- No space constraints or color figure charges

- Immediate publication on acceptance

- Inclusion in PubMed, CAS, Scopus and Google Scholar

- Research which is freely available for redistribution 